\title{
Assessing Immune Response to SARS-CoV-2 Infection
}

This article was published in the following Dove Press journal:

ImmunoTargets and Therapy

\author{
Michael R Shurin (iD) ${ }^{1,2}$ \\ Alison Morris ${ }^{3}$ \\ Alan Wells $\mathbb{D}^{\prime}$ \\ Sarah E Wheeler' \\ 'Department of Pathology, University of \\ Pittsburgh Medical Center, Pittsburgh, \\ PA, USA; ${ }^{2}$ Department of Immunology, \\ University of Pittsburgh Medical Center, \\ Pittsburgh, PA, USA; ${ }^{3}$ Department of \\ Medicine, University of Pittsburgh \\ Medical Center, Pittsburgh, PA, USA
}

In the XXI century, we have already witnessed the global spread of three previously unknown coronaviruses. In 2002, the first known case of severe acute respiratory syndrome (SARS) occurred in China and SARS coronavirus (SARS-CoV) was identified in 2003. ${ }^{1}$ Before SARS pandemic was declared to be over in summer of 2003, about 8500 cases were reported, including almost 900 deaths in 32 countries. Ten years later, in 2012, a novel coronavirus, Middle East respiratory syndrome coronavirus (MERS-CoV), was isolated and was proven to be associated with several clusters of cases, first in the Arabian Peninsula and then in other countries. As a result, almost 2500 cases including more than 850 deaths in 27 countries have been reported. ${ }^{2}$ In 2019, a novel $\beta$-coronavirus caused severe and even fatal pneumonia in Wuhan China, and rapidly spread to other provinces of China and other countries in 2020. The World Health Organization (WHO) on March 11, 2020, declared coronavirus disease 2019 (COVID-19) caused by severe acute respiratory syndrome coronavirus 2 (SARS-CoV-2) a pandemic. By mid-May 2020 , more than 300,000 people have died and over 4,000,000 have been infected by the coronavirus in almost 200 countries and territories worldwide.

Coronaviruses were first discovered in the 1930s when an acute respiratory infection of domesticated chickens was investigated, and human coronaviruses were first identified in the 1960s. ${ }^{3,4}$ These early identified human coronaviruses are circulated in the global human population and contribute to $\sim 30 \%$ of common cold infections and mild respiratory symptoms and include the coronaviruses NL63, 229E, OC43 and HKU1. ${ }^{5}$ There are only seven coronaviruses known to cause disease in humans and the remaining three, MERS-CoV, SARS-CoV and SARSCoV-2 (or 2019-nCoV), are more severe than the four relatively benign earlier counterparts. Although SARS-CoV-2 and SARS-CoV share the same host receptorthe human angiotensin-converting enzyme 2 (ACE2), ${ }^{6}$ and in spite of $\sim 80 \%$ genetic identity between SARS-CoV 1 and 2, these coronaviruses are different in several epidemiologic and biologic characteristics including transmissibility, virulence, survival, virus-host interactions and, it appears, induction of immune response and immune escape pathways.

Like SARS and MERS, SARS-CoV-2 infection manifests most frequently with lower respiratory symptoms. A minority of patients progress to acute respiratory distress syndrome with diffuse alveolar damage. Though COVID-19 symptoms, in general, have presented chiefly within the respiratory system, the infection rapidly spreads to affect the kidneys, nervous and cardio-vascular systems, clotting 
pathways, skin and the immune system in some patients. Interestingly, both lymphopenia and hyperactivation of the immune responses are reported in COVID-19 patients. Therefore, from the immunological point of view, the important question is: What do we need to know about COVID-19 immunity, and thus what should we measure in these patients?

Noticeably, the immune responses induced by SARS$\mathrm{CoV}-2$ infection seem to be in two-stages. As most of the infected individuals develop only mild or no clinical symptoms, it is conceivable that during the incubation and non-severe stages, a specific adaptive immune response is required to eliminate the virus and to preclude disease progression to severe stages. Such a robust immune response, as noted by virus-specific immunoglobulin production in these individuals, is associated with clinical recovery of most SARS-CoV-2-infected patients without severe respiratory symptoms. ${ }^{7,8}$ However, when a protective immune response is impaired, virus propagates and massive destruction of the affected tissues occurs, particularly in organs with high ACE2 expression. ${ }^{9}$ At this stage, hyperactivation of a few subsets of immune cells and the cytokine release syndrome (CRS, "cytokine storm") induces lung, intestine and kidney damage. In addition, liver injury has also been reported to occur during the course of the disease in severe cases as is seen in SARS-CoV and MERS-CoV. ${ }^{10}$ A total of 14 cytokines, from 48 analyzed, were significantly elevated in plasma in patients with COVID-19. ${ }^{11}$ Importantly, these cytokines exhibited dissimilar expression profiles in patients with different disease severity: for instance, levels of IP-10, MCP-3, HGF, MIG and MIP-1 $\alpha$ were significantly higher in critically ill patients when compared with the expression in patients with severe or moderate disease. Also, IP-10 and MCP-3 were revealed to be outstanding predictors for the progression of COVID-19 disease. Interestingly, ACE2 was shown to function as an interferon-stimulated gene in human barrier tissue epithelial cells $^{12}$ suggesting that SARS-CoV-2 may exploit IFNinduced increase in ACE2 expression, a crucial cellprotective factor in lung injury, to augment infection.

Furthermore, serum IL-6, IL-10 and TNF- $\alpha$ concentrations negatively correlated with reduced total $\mathrm{T}$ cells, $\mathrm{CD}^{+}$and $\mathrm{CD}^{+} \mathrm{T}$ cells, and survival of COVID-19 patients. ${ }^{13}$ T cells from these patients expressed high levels of PD-1, which was particularly seen as patients progressed from prodromal to overtly symptomatic stages. Thus, it is possible that the cytokine release may drive the depletion and exhaustion of $\mathrm{T}$ cells. Together with the fact that low $\mathrm{T}$ cell number and exhausted $\mathrm{T}$ cells can leave patients more susceptible to secondary infection, these results suggest that it is important now to focus on subpopulations of $\mathrm{T}$ cells in order to discover their vulnerability and their role in disease progression and recovery. Recent data demonstrated reduced COVID-19 severity in patients with respiratory allergies potentially due to the reduction in ACE2 expression in allergic individuals, ${ }^{14}$ suggesting the need to expansively assess the role of type 2 immune regulation in the pathogenesis of SARS$\mathrm{CoV}-2$ infection. At the same time, an excessive immune response contributes to SARS-CoV-2 pathogenesis and COVID-19 lethality. The rapid viral replication of SARSCoV-2 may cause fatal inflammatory responses and acute respiratory distress syndrome (ARDS) in patients. For instance, during virus replication, the released coronavirus nucleocapsid dimers may interact with mannose-binding lectin-associated serine proteases. This interaction induces over-activation of the complement system and promotes cell lysis leading to further elevation of pro-inflammatory cytokines, characterized as cytokine storm. ${ }^{15}$

Tissue damage, particularly if associated with disproportionate inflammation and CRS, may dysregulate the peripheral tolerance machinery and allow initiation or hastening of autoimmune pathways. It is also possible that despite the lymphocytopenia often seen in severe COVID-19 patients, hyperactivation of virus-specific $\mathrm{CD} 8+$ and CD4 $+\mathrm{T}$ cells during SARS-CoV-2 infection and massive destruction of infected cells may result in the development of autoimmune pathology after patient recovery. Although effective immune response against viral infections depends on the activation of cytotoxic $T$ cells that can clear the infection by killing virus-infected cells, very little is known about viral protein-specific $\mathrm{T}$ cells in CoVID-19 patients. Furthermore, it is not yet clear whether these cells play a role in the elimination of SARSCoV-2-infected cells and/or massive destruction of infected cells in different tissues. Again, a comprehensive analysis of $\mathrm{T}$ cell subsets in COVID-19 patients, especially after recovery, is justified to predict and minimize outcomes of immune dysregulation during infection.

In spite of a growing body of immunological data associated with SARS-CoV-2 infection, it is still not completely understood how the infection is cleared. ${ }^{16}$ If SARS-CoV-2, similar to other coronaviruses, induces an acute infection which is then completely cleared by the immune system, 
then the majority of recovered individuals should acquire at least a temporary immunity and be protected from a repeated infection for some time. Another scenario is viral latency, when the virus may lie dormant within a cell as the viral genome has not been fully eradicated. The virus is still able to reactivate via external activators, as seen in herpes simplex virus, which commonly infects an individual for life. Another scenario is a chronic infection, such as in the case of viral hepatitis and HIV, when a virus persists for a continued period and causes long-term inflammation and damage. This limited understanding of SARS-CoV-2 behavior suggests the necessity to develop verified immunoassays to assess the circulation of both anti-viral antibodies and viral proteins (antigens) as in the case of HBV and HIV infections. As many unknowns remain about antibody tests, determination of several subclasses of immunoglobulins - IgG, IgM and IgA, recognizing at least SARS-CoV-2 specific spike and nucleocapsid proteins - is urgently needed to unravel the development and stability of immune response to SARS-CoV-2 infection. These clinical data should support the development of alternative fast, reliable and non-expensive testing of the neutralizing potential of tested anti-viral antibodies. This information also is needed for a better understanding of the applicability of a phenomenon known as antibody-dependent enhancement, when pathogen-specific antibodies can promote pathology, ${ }^{17}$ to SARS-CoV-2 infection and COVID-19 severity. The results of wide antibody testing should provide information on disease prevalence and the frequency of asymptomatic infections. Finally, the determination of spike, nucleocapsid and envelop proteins of SARS-CoV-2 in serum/plasma samples is also urgently needed to support expanded screening of different populations of people for epidemiologic, predictive, and risk evaluating studies. Further elucidation of these complex clinical data will identify novel diagnostic and therapeutic strategies to more effectively control this pandemic and prevent its potential recurrence.

\section{Disclosure}

The authors report no conflicts of interest in this work.

\section{References}

1. de Wit E, van Doremalen N, Falzarano D, Munster VJ. SARS and MERS: recent insights into emerging coronaviruses. Nat Rev Microbiol. 2016;14(8):523-534. doi:10.1038/nrmicro.2016.81

2. Al-Tawfiq JA, Zumla A, Memish ZA. Coronaviruses: severe acute respiratory syndrome coronavirus and Middle East respiratory syndrome coronavirus in travelers. Curr Opin Infect Dis. 2014;27 (5):411-417. doi:10.1097/QCO.0000000000000089

3. Estola T. Coronaviruses, a new group of animal RNA viruses. Avian Dis. 1970;14(2):330-336. doi:10.2307/1588476

4. Kahn JS, McIntosh K. History and recent advances in coronavirus discovery. Pediatr Infect Dis J. 2005;24(Supplement):S223-227. doi:10.1097/01.inf.0000188166.17324.60

5. van der Hoek L. Human coronaviruses: what do they cause? Antivir Ther. 2007;12(4 Pt B):651-658.

6. Hoffmann M, Kleine-Weber H, Schroeder S, et al. SARS-CoV-2 cell entry depends on ACE2 and TMPRSS2 and is blocked by a clinically proven protease inhibitor. Cell. 2020;181(2):271-280.e8. doi:10.1016/j.cell.2020.02.052

7. Cunningham AC, Goh HP, Koh D. Treatment of COVID-19: old tricks for new challenges. Crit Care. 2020;24(1):91. doi:10.1186/ s13054-020-2818-6

8. Thevarajan I, Nguyen THO, Koutsakos M, et al. Breadth of concomitant immune responses prior to patient recovery: a case report of non-severe COVID-19. Nat Med. 2020;26(4):453-455. doi:10.1038/ s41591-020-0819-2

9. Shi Y, Wang Y, Shao C, et al. COVID-19 infection: the perspectives on immune responses. Cell Death Differ. 2020;27(5):1451-1454. doi:10.1038/s41418-020-0530-3

10. Zhang C, Shi L, Wang FS. Liver injury in COVID-19: management and challenges. Lancet Gastroenterol Hepatol. 2020;5(5):428-430. doi:10.1016/S2468-1253(20)30057-1

11. Yang Y, Shen C, Li J, et al. Plasma IP-10 and MCP-3 levels are highly associated with disease severity and predict the progression of COVID-19. J Allergy Clin Immunol. 2020. doi:10.1016/j. jaci.2020.04.027

12. Ziegler C, Allon SJ, Nyquist SK, et al. SARS-CoV-2 receptor ACE2 is an interferon-stimulated gene in human airway epithelial cells and is enriched in specific cell subsets across tissues. CELL. 2020;181 (5):1016-1035.e19. doi:10.1016/j.cell.2020.04.035

13. Diao B, Wang C, Tan Y, et al. Reduction and functional exhaustion of $\mathrm{T}$ cells in patients with Coronavirus disease 2019 (COVID-19). Front Immunol. 2020;11. doi:10.3389/fimmu.2020.00827

14. Jackson DJ, Busse WW, Bacharier LB, et al. Association of respiratory allergy, asthma, and expression of the SARS-CoV-2 receptor ACE2. J Allergy Clin Immunol. 2020. doi:10.1016/j.jaci.2020.04.009

15. Tok TT, Tatar G. Structures and functions of coronavirus proteins: molecular modeling of viral nucleoprotein. Int $J$ Virol Infect Dis. 2017;2:001-007.

16. Cyranoski D. Profile of a killer: the complex biology powering the coronavirus pandemic. Nature. 2020;581(7806):22-26. doi:10.1038/ d41586-020-01315-7

17. Iwasaki A, Yang Y. The potential danger of suboptimal antibody responses in COVID-19. Nat Rev Immunol. 2020. doi:10.1038/ s41577-020-0321-6 


\section{Publish your work in this journal}

ImmunoTargets and Therapy is an international, peer-reviewed open access journal focusing on the immunological basis of diseases, potential targets for immune based therapy and treatment protocols employed to improve patient management. Basic immunology and physiology of the immune system in health, and disease will be also covered. In addition, the journal will focus on the impact of management programs and new therapeutic agents and protocols on patient perspectives such as quality of life, adherence and satisfaction. The manuscript management system is completely online and includes a very quick and fair peer-review system, which is all easy to use. Visit http://www.dovepress.com/testimonials.php to read real quotes from published authors.

Submit your manuscript here: http://www.dovepress.com/immunotargets-and-therapy-journal 